\title{
Correction to: Subsequent Migration of Immigrants Within Australia, 1981-2016
}

\author{
James Raymer $^{1}$ [D $\cdot$ Bernard Baffour $^{1}$
}

Published online: 31 August 2018

(c) The Author(s) 2018

\section{Correction to: Population Research and Policy Review https://doi.org/10.1007/s11113-018-9482-4}

The article Subsequent Migration of Immigrants Within Australia, 1981-2016, written by James Raymer and Bernard Baffour, was originally published electronically on the publisher's internet portal (currently SpringerLink) on 31st July 2018 without open access.

With the author(s)' decision to opt for Open Choice the copyright of the article changed on August 2018 to (C) The Author(s) 2018 and the article is forthwith distributed under the terms of the Creative Commons Attribution 4.0 International License (http://creativecommons.org/licenses/by/4.0/), which permits use, duplication, adaptation, distribution and reproduction in any medium or format, as long as you give appropriate credit to the original author(s) and the source, provide a link to the Creative Commons license and indicate if changes were made.

The original article can be found online at https://doi.org/10.1007/s11113-018-9482-4.

The original article has been corrected.

James Raymer

james.raymer@anu.edu.au

Bernard Baffour

bernard.baffour@anu.edu.au

1 School of Demography, Australian National University, 9 Fellows Road, Acton, ACT 2601, Australia 